\title{
Psychological Ramifications of Trauma in Women as Represented in Shahnaz Bashir's The Half Mother
}

\author{
Dr Zeenat Khan \\ Sr. Assistant Prof - English \\ Mehr Chand Mahajan DAV College for Women \\ Chandigarh, India \\ zeenumcm@gmail.com
}

\begin{abstract}
Trauma is a subjective and extensive term with its diverse implications on individuals and consequently on the societies. Also the heterogeneity of traumatic experiences, cannot be over-simplified by putting them under one blanket term or generalising all of them into one bracket. Since nineteen nineties, owing to several reasons, the term trauma has picked up an impetus, and various studies in this area of discourse are being carried out. Recently only however homogenising of all the traumatic experience into the countable postulates of Literary Trauma Theory is being challenged by the scholars and academicians across the world.

In this paper, trauma of an individual (who is a single mother) and a society (of Kashmir) through the reading of Shahnaz Bashir's The Half Mother is explored. This paper shall try to map the mindscape of the protagonist Haleema and parallelly observe the cultural ramifications of the same.
\end{abstract}

Keywords: Trauma, Women, Trauma Theory, Narrative, Society, Culture 
Introduction:

The colour of everything is sorrow

the colour of the moon is sorrow

the colour of the streets is sorrow and

the colour of memories is sorrow

The colour of my heart, in its own heart, is sorrow.

The colour of my breath is sorrow, the colour of sorrow is sorrow

The above lines from The Half Mother (Bashir 5) reflect on the ramifications of loss and trauma that an individual suffers. Be it the heavenly world i.e. the "moon" or this world i.e. the "streets" or inside of the person i.e. the "memories", "heart" and "breath" , the sorrow in the life of sufferer, Haleema, is three dimensional as depicted in above quoted lines. All the things seem to be coloured in one hue- that is of a perpetual sorrow. An all-encompassing pain engulfs the life of the victims and witnesses of traumatic event. This paper is an attempt to study the narrative of trauma and its psychological ramifications in Shahnaz Bashir's The Half Mother. The novel will be explored on two levels, one individual and another collective i.e. the society. Through this novel the agony and trauma of distressed individuals like Haleema and cracked social fabric of Kashmir will be studied. The novel along with depicting stress and pain in individuals especially women, also is an example of the transformative shift in literary as well as cultural scene of Kashmir. From writing and celebrating the beauty and richness of the beautiful vale to a trauma-ridden and psychologically stressed out society is evident. Consequently the contemporary Kashmiri literary scene is majorly now a chronicle of pain and trauma. These novels depict individual as well as collective nature of trauma. The trauma of victims flows across the cultures and majority of the sufferers share almost similar fate as we see in these novels. Also it is 
conspicuous to note that the silence of victims and the intense psychological bearings of trauma remain universal, nevertheless both silence and expression vary from culture to culture. The perpetual collective trauma is shared by all segments of the society and women being the worst sufferers in most of the cases.

In a social and cultural set up where a woman anchors her existence to her husband and her children, understandably the loss of both proves to be detrimental to her on both levels- personal and social. In the very first chapter titled'A reverie in retrospect' Haleema is seen as a person who hates herself. "She woke up hating herself ... She hated the moon now"(3), these sentences point toward a grave psychological crisis where a woman starts disliking everything so much so that she begins despising herself. Yet Haleema relentlessly struggles against all odds. Her eyes are the eyes of a mother as"her eyes did not leave her wooden gate" (4), she remains sombrely hopeful for the return of her disappeared son, Imran, while running pillar to post to find him. Perpetually, "her head was filled with flashing visions and buzzing memories", which added to her woes. The "Pathogenic memories" ( Breuer and Freud 40)keep haunting her day and night and keep coming back to prick her gaping wounds in sudden but repetitive flashes.

Haleema's pain is an ongoing pain and an everyday struggle. One thing may be noted here about the conflict zones is that the similar happenings in the surroundings amplify the pain of an individual as he/she finds similitude of hopelessness and despair in their own suffering and that of the others. Shahnaz Bashir has represented this collective social and cultural crisis through the story of Haleema. The never-ending search for the loved ones especially, fathers, husbands, brothers and sons, has become a special case of Kashmir specific trauma that has impacted its women in the most detrimental way. They often spend remaining lives hopelessly searching for their missing men. Along with emotional bereavement, women suffer financial crisis because men, the bread-earners of the family, are 
lost. This pain and trauma takes further complicated dimensions when in the search of finding their loved ones they have to bear the sexual advances as well. The lecherous people like Bhat as depicted in The Half Mother are found in every nook and corner of the society, who are ready to pounce upon their easy and vulnerable preys, like Haleema. For instance, when she visits a politician, Bhat, in hope of getting his help in finding her lost son, Imran, Bhat chuckles suggestively, "You are wasting your beauty and time in vain ... Don't you think if we two meet, we can find him in a day? Just think..." (83), she does not react to his despicable proposal but is lost in politician's fake assurance of finding her son.

Trauma of Haleema and many women like her keeps compounding with every passing day. The case study of Haleema in The Half Mother can be seen as a blue print for the study of a social set-up as well. She is an individual with her own personal struggles and past but she is also a prototype of women of the society in general. Thus the novel The Half Mother, " breed(s) the feelings of collective and cultural trauma, where fictional narratives take the responsibility of presenting the reality of life as it is. Through such memories of the traumatic past, the factual tale of psychological sufferings is unveiled"( Hanif \& Inayat Ullah: $\mathrm{np})$

\section{Literature Review}

Contemporary Kashmiri novels represent the psychological ramifications of their trauma in a global language i.e. English along with Urdu and Kashmiri as "Kashmiris have begun to reflect on the conflict in which they have been engulfed since 1989 in a variety of literary narratives that include poetry, novels, and shorts stories. Written in Kashmiri, Urdu, and English, these literary narratives struggle to give voice to the individual and social suffering caused by the conflict"(Zutshi np). This has also led to an increased global interest of scholars working in the field of literary trauma studies. Narratives about wars, conflict 
zones, violence have led to asurge in all forms of literature that represents trauma surroundings such incidents and situations. Similarly, an upsurge is also seen in young and educated Kashmiri people writing about themselves.

Novels like Waheed Mirza 's The Collaborator, Basharat Peer's Curfewed Nights, Sidhhartha Gigoo's The Garden of Solitude narrate the pain of Kashmiris both Pandits and Muslims. They use the narratology of trauma and engage with their collective trauma which is now part and parcel of the Kashmiri psyche. The narratives like The Half Mother and those cited above are literary representations of individual as well as collective trauma that is an on-going trauma and is without any closure.

The Half Mother: A Tale of Pathological Memories

Set in Natipora area of Srinagar, The Half Mother by Shahnaz Bashir, is a story of a traumatic aftermath of an excruciatingly painful event in the life of a Kashmiriwoman, coupled with an intensely grim scenario which doesn't allow her any respite. The protagonist of the novel, Haleema, lives a life in a limbo after her only son, the 'apple of her eyes', disappears. Imran, son of Haleema, grew in 90s in an atmosphere of tensions and horror. A life-long tragedy for Imran and his mother Haleema started when, during winters, Imran, had an ugly skirmish with army men. Imran, being a very young teenaged boy,could not bear the humiliation of Ab Jaan (his maternal grandfather) and"furiously sprinted towards the trooper who had punched Ab Jaan, ramming into his legs and pummelling his thigh" (27). This episode made them conspicuous in the eyes of Major Kushwaha, who kept vengeful feelings against Imran and his Ab Jaan. Some days later, a patrolling party led by Major Kushwaha came crashing down on Natipora, severely thrashing people in its search operation. It entered forcefully into Haleema's house, and a heated argument with Ab Jaan ensued. Major Kushwaha, "hit Ab Jaan on the arm with his rifle" (48), shouting, "Don't lie, All you 
sisterfucking Kashmiris lie! ... Tell me, or I' 11 shoot you. (48). After few scuffles and shouts, "three bullets were pumped into Ab Jaan" (49). Imran had frozen with shock, from happy and jovial young boy he changed into a silent and morose boy. Few days after this wrecking episode of brutality, troops forcibly rammed into their house again, and snatched away Imran, Haleema's only son. They took Imran with them. Haleema pleaded, begged and did all she could do but they did not listen. Imran shrieked, "Ammi! Save me!"(58), but her son was pulled away from her to unknown dungeons. Haleema was left all alone, her father Ab Jaan murdered brutally and her son disappeared. She was left with an excruciating pain, alone and restless for ever. Thereon starts her hopeless search and mission of tracing her son in prisons, police stations and mortuaries all over the valley. From politicians to journalists she keeps making rounds to every possible corner under the sun, where she could get someclue of Imran's whereabouts, her beautiful and obedient teenaged son.

Trauma that Haleema suffers is inexpressible. It remains like a cut open wound which could never heal. Lonely Haleema there on always remains lost in the past. The memories keep haunting her. When not on search, her mind's only occupation was recalling memories of her dead father Ab Jaan and her disappeared son Imran. These memories kept coming back to her and rendered her wounds more fresh and agonising than before. These 'pathogenic memories' wrecked her every night and visited her when, "She laid out the utensils to serve herself dinner, she ladled the rice onto two plates ... she stopped ... She began to sob, followed by a low wail that reverberated in the empty house"(108-109). She was always alerted, "when someone knocked at the door, she would quickly feel her heart sank. Her brain would blow over and over, It is him, maybe it is him. She would get weak in the knees; her hands would tremble" (112). Thus Bashir's narrative of Haleema's story like other contemporary Kashmir fiction echoes "narratives (that) are haunted by a sense of temporal suspension or delay, as trauma plays itself out within them. Waiting, often endless in its 
anticipation, defines the existence of many of the characters in the novels"(Zutshi np) as the memories were link between mother and her son, "separated by long years of separation" (111), Haleema sometimes also recalled how "her childhood and that of her son in their house encircled by a plum orchard, listening to stories told by her father, or playing with chickens in the courtyard"(Zutshi np) was beautiful and joyous, but soon she was engulfed by the same trauma- ironically full of void.

Such trauma involves much more pain than a single traumatic event or experience, as every day memories of the trauma without any closure, cause an agonising negative consequences which are worse than death for Haleema. Imran is not dead but has 'disappeared'. The traumatic memory of the fateful day when Imran was snatched away from her, the questions regarding his current whereabouts and condition and the everyday struggles of finding and dealing with obnoxious politicians aggravate the psychological stress and trauma. This kind of trauma is " much more than a pathology, or the simple illness of a wounded psyche"(Caruth 4). Haleema becomes silent and paranoid in the end, as such " radically disorienting experience of trauma often involves a dissociation between cognition and affect" (Stef Craps and Lucy Bonds 77).

Haleema's Psychological Trauma: An Agonising Never-ending Wait

The helplessness, silence and voicelessness of the victims like Haleema, their psychological and emotional rupture and their circumstantial stand stillness, leads to a detrimental and irrecoverable psychosis. The story of Haleema is an epitomic literary representation of women in a disintegrated society. Such trauma is seen not only as representing "historical wounds" for particular communities, but rather it unfolds in the aftermath of the events, and is traumatic precisely in its inability to be captured and recorded. The narratives are thus replete with the impossibility of writing trauma and thereby 
of possessing it, and ultimately, of the impossibility of accessing the traumatized self itself"(Zutshi np). Bashir's novel is representative of the trauma that is inexpressible, it leads to overall ill psychological health of women and hence the whole Kashmiri social fabric. The symptoms "like stress, depression and trauma" are common and there is an increased "number of cases related to abortion and miscarriages among women"(Mir \& Somasundran134). Various literary, psychological and social studies are being carried out in the region to entail an insight into the gendered response to psychological trauma. It is an universally acknowledged fact that women being the centre of hearth and home,especially in Indian social structure, suffer a psychological and emotional rupture. Living with paranoia, amounts to halting of a life. Sometimes "the societal pressure, cultural inhibitions and the indifferent attitude of their family members put(s) them in a state of complete distress. It has also (been) found from the field that the traumatic experiences in the life of women have created problems in the average psychological performance in day to day life (Mir \& Somasundran 139). Thus traumatic memories, social bearings and the belatedness of trauma stokes in the psyche of female characters like that of Haleema in The Half Mother.Studies and reports show that,

"the level of psychological impact due to armed conflict on women is high among the majority $(83.8 \%)$ of the respondents. The study also has shown that the majority of the respondents are found to have suffered in the form of a feeling of hopelessness \& helplessness, sleep disturbance, unable to concentrate, feeling nervous, tense or worried and loss of interest in life, loss of interest in things. The study also shows that a large number of respondents suffer from psychological problems due to the death or disappearance of their family member"(Mir \& Somasundran 141). 
Women of Kashmir be they Muslim, Hindu, Sikh or Buddhist have been worst victims of terror and turbulent history as found in the contemporary literature written by Kashmiris. Kashmiri women's psychological representation in the given texts is authenticated by various sociological and psychological studies in this area. The "traumatic events can have a profound and lasting impact on the emotional, cognitive, behavioural and physiological functioning of an individual. No age group is immune from exposure to trauma, and its consequences"( Amin, S. \& Khan, A. W np). A study shows that, "women have a higher prevalence of depression in all the age groups than males and it is highest in the age group 26 to 35 years $(68.66 \%)$. Women in the age group of $15-25$ years also have similar prevalence rate of depression (68.64\%)"( Amin, S. \& Khan, A. W np). This trauma is passed onto the next generations and seeps into the familial unit of the society. The cultural response, the family ties, the rituals, the religious cohesion have women in the centre in the societal structure of Kashmir, therefore, "intergenerational and collective trauma deserve greater focus in the context of protracted conflicts"(Housen, T., Lenglet, A., Shah, S. et al).

As cited in $W M C$, "50 percent of women (compared to 37 percent of men) suffered from probable depression; 36 percent of women (compared to 21 percent of men) had a probable anxiety disorder; and 22 percent of women (compared to 18 percent of men) suffer from post-traumatic stress disorder (PTSD)"(Mir Shoaib Mir \& ParthuVenkatashnp). Prolonged exposure to tragic and horrific incidents led to psychological effects which are profound and lifelong. The victimhood of women leads to crumbling down of social structures and their trauma seeps silently into the societies and generations. Though (un)speakability and silence of Kashmiri women find voice through the narratives of Kashmiri writers, but the unexplainable and deeply inflicted psychological wounds of the ongoing and perpetual trauma can't be fully expressed ever. Nevertheless, literature becomes the mouthpiece for the victims like Haleema and has a cathartic effect too for the shared pain 
of society. Thus narration of the events in the trauma literature can be read on the several levels. From the lens of literary trauma theory, the dominant themes of psychological trauma, post-traumatic stress disorders, and continuous traumatic stress syndrome can be explored with a comprehensive understanding of trauma and its memory. 
Works Cited:

Amin, S. \& Khan, A. W. "Life in Conflict: Characteristics of Depression in Kashmir". International Journal of Health Sciences. 3(2), 2009,213-223.

Bashir, Shahnaz. The Half Mother. Hachette Book Publishing, 2014.

Breuer, Joseph and Sigmund Freud. 1955 [1895]. "Studies on Hysteria." In Standard Edition of the Complete Psychological Works of Sigmund Freud. Vol. 2, trans. James Strachey. London: Hogarth Press.

Bond, Lucy and Stef Craps. Trauma. Routledge, 2020.

Caruth, Cathy. Unclaimed Experience: Trauma, Narrative and History. The Johns Hopkins UP, 1996.

Housen, T., Lenglet, A., Shah, S. et al. "Trauma in the Kashmir Valley and the mediating effect of stressors of daily life on symptoms of posttraumatic stress disorder, depression and anxiety". Confl Health 13, 58 (2019)

Hanif, Samia, and Inayat Ullah. "War Trauma, Collective Memory, and Cultural Productions in Conflict Zones: Kashmir in Focus."SAGE Open, July 2018. https://journals.sagepub.com/doi/full/10.1177/2158244018800912

Mir, Bilal Ahmad and K. Somasundaran. "Psychological Impact Among Women Due to Armed Conflict in District Shopian, Jammu and Kashmir". MDUR Journal ARTS. Vol.18 (1), 2019. http://www.mdu.ac.in/Journals/about.html.

Mir, Shoaib and Parthu Venkatesh P. "The Silent Mental Health Crisis Among Women in Kashmir". Women's Media Center. https://womensmediacenter.com/women-under siege/the-silent-mental-health-crisis-among-women-in-kashmir 
Zutshi, Chitralekha, Kashmir Journal: traumatic pasts in Kashmiri fiction". Kashmir Connected, Jan 2016. http://www.kashmirconnected.com/traumatic-pasts-in-kashmiri fiction.html. 